\title{
PRENSA Y CREACIÓN LITERARIA EN EL XVIII ESPAÑOL
}

ANA Mª Freire LÓPEZ

UNED

I. LA ILUSTRACIÓN Y LA INDUSTRIA EDITORIAL: EL LIBRO

El fenómeno de la Ilustración caracteriza al XVIII europeo, y al español, aunque se haya debatido tanto sobre el carácter de la Ilustración española.

De lo que no cabe duda es de que en la difusión del nuevo espíritu, de las nuevas ideas, tuvo una función muy destacada el papel impreso, en su modalidad de libro o folleto, y de una manera muy particular en la vertiente del periodismo, que adquiere en este siglo una pujanza antes desconocida en España. La prensa periodica fue indudablemente uno de los cauces de la Ilustración, y en sus páginas laten las nuevas corrientes de pensamiento de una forma que no se encuentra en el libro.

En el siglo XVIII, en España se leía poco. François López, que ha dedicado notables trabajos a la historia del libro español, y en particular al del siglo que nos ocupa, ha podido comprobar -a partir de la documentación que generaron las medidas del Juez de Imprentas Curiel- que en la década de los 50 (en los años 1757-58) había en toda España, solo «unas 180 librerías, pobres, decentes o muy florecientes. Las ciudades en las que mayor número había de ellas eran, por orden de importancia: Madrid, Barcelona, Valencia, Valladolid, Sevilla, Cádiz, Zaragoza, Granada, Salamanca. En total eran cuarenta 
las ciudades en que algún comercio de librería existía de manera fija» ${ }^{1}$. Nada más. Y esas 180 librerías eran menos que las que en esos mismos años existían en la ciudad de París. Téngase en cuenta además que los libreros y los impresores eran las mismas personas. La industria editorial no se independiza de la librería hasta bien entrado el siglo XIX.

En 1979, un equipo de la Universidad de Oviedo llevó a cabo un detallado estudio ${ }^{2}$, cuyos resultados muestran que en la década inmediatamente anterior -de 1745 a 1755-, el total anual de títulos publicados en España oscilaba entre 249, el año que menos (1749), y 447, el que más (1746). Ya antes Richard Herr, en su conocido estudio España y la revolución del siglo XVIII -la primera edición es de 1960- había señalado que entre 1784 y 1785 se publicaron en España aproximadamente 460 libros (no explica si incluye folletos, en cuyo caso debería decir 460 títulos), de los que más de un tercio, unos 160 , tenían un contenido religioso, «colecciones de sermones, vidas de santos, libros de oraciones, tratados teológicos». Herr se apoya para aportar estos datos en la Biblioteca periódica anual, de la que luego hablaremos. De esos libros -cito a Herr-:

Aproximadamente siete por ciento eran cientificos, y los dedicados a temas industriales, artísticos o comerciales, apenas pasaban de un tres por ciento. La medicina era un tema que tenía aceptación (9 por 100 ), pero no era nuevo, aunque indudablemente los trabajos reflejaban progreso en esta rama de la ciencia. Un escueto dos por ciento de los libros discutían los problemas filos6ficos (principalmente la moral) fuera del límite de la religión ${ }^{3}$.

Pero en España se leían -se vendían, se compraban- también libros editados fuera del país. François López, tomando como punto de partida la Gaceta de Madrid y la Biblioteca periódica anual, estudió estadísticamente las obras anunciadas entre los años 1784-1788. En total -libros españoles y libros extranjeros, de todas las materias- suman 1.200 , que clasificados por materias arrojan unos resultados muy interesantes:

1 FrançOIS LOPEZ, «Los vehículos de la Ilustración». Ponencia inédita en el Congreso Internacional sobre el concepto de llustración Española. Oviedo, 1985.

2 Immaculada Urzainqui Miqueléz, Jesús Menéndez Pelaez, Álvaro Ruiz de la Peña y JUAN FERNANDEZ GÓMEZ, «La producción de libros de 1745 a 1755. Contribución a una encuesta bibliográfican, en La época de Femando VI (Textos y Estudios del Siglo XVIII, núm. 9), Oviedo, Cátedra Feijoo, 1981, págs. 21-56.

3 RICHARD HERR, España y la revolución del siglo XVIII, Madrid, Aguilar, 1988, pág. 160. 
Teología y religión: 234 títulos (19'5\% del conjunto)

Derecho y jurisprudencia: 45 títulos (3'7\% del total)

Historia y geografía: 146 átulos (12'1\% del conjunto)

Ciencias y artes: 393 títulos (32'7\% del conjunto)

Bellas letras: 382 títulos $\left(31^{\prime} 7 \%\right.$ del total) ${ }^{4}$.

Teniendo en cuenta que muchos de esos libros eran extranjeros -en su mayor parte impresos en Francia-, resulta explicable que las cifras de edición al otro lado de los Pirineos (Francia, Suiza...) en el siglo XVIII sean mucho más elevadas, dado que se abastecían a sí mismos y además exportaban. En Francia se publicaban, a principios de siglo, unos 1.000 libros al año (solo libros, sin contar folletos); entre 3.000 y 4.000 en la década de los años 60 (17601770); y esas cifras aumentaron en vísperas de la Revolución francesa.

La política de publicaciones en la España del XVIII muestra, sin embargo, una creciente familiaridad con el papel impreso, a pesar de los pesares. El mayor de esos pesares era el analfabetismo, que por término medio afectaba a un 80 por ciento de la población, una población que se incrementó notablemente desde los ocho millones de habitantes de principios de siglo, hasta los cerca de 11 que había al terminar. La mayor parte de los lectores pertenecía a las clases privilegiadas, con inquietud y preparación intelectual; pero desde arriba -de acuerdo con los planteamientos ilustrados- se tomaron algunas medidas para que también las clases menos favorecidas tuvieran acceso a la lectura. En tiempos de Carlos III se ordenó a los obispos que crearan bibliotecas públicas a su costa, pero Domínguez Ortiz afirma que apenas existen datos para verificar el cumplimiento de tal mandato ${ }^{6}$. El mismo autor señala que las bibliotecas públicas, al parecer, no cumplían su papel, y aunque las órdenes religiosas ponían sus bibliotecas a disposición de los lectores, los fondos eran muy restringidos, temáticamente hablando, porque había pocas obras profanas, científicas o extranjeras. Las bibliotecas más valiosas eran las de los jesuitas y sus fondos incrementaron los de las Universidades cuando aquéllos fueron expulsados en 1767.

4 FRANÇOIs LOPEZ, «Las obras extranjeras anunciadas en la Gaceta de Madrid. Estudio diacrónico. Elementos de una estadísticas, en Periodismo e llustración en España -de ahora en adelante PIE- (núm. 52/53 de Estudios de Historia Social, enero-junio de 1990), Madrid, Ministerio de Trabajo y Seguridad Social, págs. 303-311.

5 Cfr. Histoire de l'édition française, sous la direction générale de HENRI-JEAN MARTIN et ROGER CHARTIER en collaboration avec JEAN-PIERRE VIVET, Tome II (Le livre triomphant (I660 1830), París, Promodis, 1984.

6 Antonio DomínGuez ORTL, Carlos III y la España de la Ilustración, Madrid, Alianza Editorial, 1989, pág. 181. 
La importancia que se concedio a las bibliotecas pone de relieve ese culto al libro, al papel impreso como cauce de una nueva visión de las cosas. De hecho se han extraído conclusiones -no por lo parciales menos relevantes- para el conocimiento del fenómeno ilustrado, a partir de la investigación de bibliotecas privadas, como la de Jovellanos, estudiada por Aguilar Piñal ${ }^{7}$, que en 1778 constaba de 857 obras impresas -manuscritos aparte- en varios idiomas, la mayor parte editadas en el extranjero. Por cierto, que buena parte de los ejemplares con que comenzó a formarla en Sevilla procedían de antiguas bibliotecas de los jesuitas. También han sido objeto de diversos estudios las bibliotecas de otros literatos e ilustrados como Olavide, Meléndez Valdés o Mayans; y, más parcialmente, la del padre Flórez, la del padre Isla, la de Feijoo, la de Sarmiento, la de Campomanes, la de Forner... 8.

Otra medida que evidencia la veneración al libro como elemento de cultura y, por tanto, de progreso, fue la creación por Felipe $\mathrm{V}$ de la Biblioteca Real, en 1711, seguida de un Real Decreto cinco años después (26 de julio de 1716) por el que se ordenaba entregar a esta biblioteca un ejemplar encuadernado de cada libro que se imprimiera.

Todos estos datos servirán para situar en su contexto el desarrollo de la prensa y el creciente interés por la lectura a lo largo del siglo.

\section{El DESARRollo DE LA PRENSA PERIódica}

La etapa más floreciente del periodismo del XVIII en España fue sin duda el reinado de Carlos III, que coincide con el auge del movimiento ilustrado en España. En realidad los Borbones -la corona- eran, a su manera, partidarios de la prensa, por lo que veían en ella de posibilidad de progreso, de modo que los frenos que encontró la prensa en el XVIII procedieron más bien del Consejo de Castilla.

El auge de la prensa en los casi treinta años del reinado de Carlos III tiene mucho que ver con la prosperidad económica que España alcanzó entonces, con el incremento demográfico -lo cual implica mayor demanda-, y sobre todo con la protección real al proyecto ilustrado, a través de medidas legales beneficiosas para la imprenta.

7 Francisco agullar Piñal, La biblioteca de Jovellanos (1778), Madrid, CSIC, 1984.

8 A este propósito véase F. Aguilar Piñal, op. cit., págs. 10-11. 
En la primera mitad del siglo varios hitos jalonan el camino que conduce a este despegue de la prensa en el reinado de Carlos III.

Salvo casos aislados, el reinado de Felipe $V$ es un erial periodístico, en pequeña parte a causa de la censura y en una mucho mayor por la crisis económica, que parece más determinante: escasez de papel y de imprentas, y el riesgo suponía para un particular embarcarse en la aventura de fundar un periódico, sin un público asegurado y con todos los riesgos que el editor corría, como veremos. Así que, en los años anteriores a 1737, prácticamente no existieron más que gacetas, o sea, periódicos oficiales.

El primer hecho importante es la creación, en 1737, del Diario de los literatos. Es verdad que lo había precedido Memorias eruditas para la crítica de Artes y Ciencias, iniciada en 1736 por Martínez Salafranca, pero su calidad era muy inferior. El Diario de los literatos era en realidad una revista, con periodicidad trimestral a pesar de su título, que seguía el modelo del Journal des Savants y de las Mémoires de Trévoux francesas. Es la primera de esta índole en nuestro país. El Diario de los literatos y las Efemérides barométrico-médicas matritenses, que tenía carácter científico, y que nace el mismo año, marcan un cambio de rumbo en el periodismo español.

El Diario de los literatos da nombre a todo un periodo de su historia: la época del Diario de los literatos, término acuñado por Guinard, al que vamos a seguir en la periodización de la historia de la prensa en el XVIII español9. Aunque el Diario dejó de existir en 1742, esa época de la prensa española abarca hasta 1759, fecha del advenimiento al trono de España de Carlos III. Es una etapa caracterizada por la escasez de periodicos, en la que, sin embargo, hay que añadir a la prensa oficial el nacimiento de esta nueva prensa de contenido literario (en el sentido amplio que el término tiene en el XVIII), y científico.

A la época del Diario de los literatos sucede la de El Pensador, editado por Clavijo y Fajardo, que es el de más calidad entre los periódicos llamados «espectadores», nombre que se les dio en España a los que imitaban o seguían de algún modo la línea del Spectator, creado en Inglaterra por Addison, Steele y otros colegas. La época de El Pensador puede darse por terminada con la desaparición, en 1771, del Correo General de España, de Mariano Nifo.

La última etapa del periodismo dieciochesco es la protagonizada por $E l$ Censor (1781-1808), semanario que encarna mejor que ninguna otra publicación la España ilustrada. Esta época podría llamarse también la del Memorial literario, de vida algo más corta, pero no por ello menos interesante, del que

9 Cfr. Paul GuINARD, La Presse espagnole de 1737 à 1791. Formation et signification d'un genre, Paris, Institut d'Études Hispaniques, 1973. 
después hablaremos. El cambio de actitud en las medidas legislativas relativas a la prensa posibilita un desarrollo notable en todos los sentidos.

El florecer de la prensa se da, pues, en el reinado de Carlos III. Ya en 1752 la reorganización de la censura supuso un paso adelante, pero es bajo el gobierno de Carlos III cuando tienen lugar disposiciones verdaderamente provechosas para los empresarios, y en definitiva para el periodismo.

La desaparición de la tasa (precio oficial de los libros y de los periódicos) en 1762, fue beneficiosa para los editores, que además pudieron adquirir las licencias de impresión a más bajo precio. También les favoreció el descenso de las tarifas postales y la implantación del sistema de suscripciones, inaugurado en 1760 por el Cajón de sastre literario, de Mariano Nifo. Es verdad que con la supresión de la tasa los periódicos se encarecieron y algunos llegaron a duplicar su precio de venta, pero el periódico en el XVIII español nunca dejó de considerarse casi un artículo de lujo, propio de naciones ricas. Por otra parte, los editores no tenían muchas alternativas si querían mantener su empresa en marcha, ya que el único ingreso que entonces obtenían era el mero producto de la venta de los ejemplares: la publicidad no se conocía -no existió hasta muy entrado el siglo XIX-, y solo contadas publicaciones tenían un mecenas ${ }^{10}$.

En cuanto a la censura de prensa, también mejoraron las cosas, al pasar a depender de nuevo, en 1764, del Consejo de Castilla, después de una dura y larga temporada de once años (1752-1763) en manos del Juez de Imprentas Juan Curiel $^{11}$. El trámite ordinario consistía -antes de Curiel- en que todo impreso que pretendiera editarse debía pasar por el Consejo de Castilla, que nombraba unos censores y después concedía o no el permiso de publicación, pero de las publicaciones periódicas solía encargarse el Juzgado de Imprentas, una especie de delegación del Consejo. En tiempos de Curiel, el Juzgado fue adquiriendo cada vez más competencias, llegando a disfrutar de gran autonomía. Finalizada esa etapa, y ya de nuevo la censura de prensa en manos del Consejo de Castilla, éste se vio desbordado por las proporciones que había adquirido la prensa, hasta el punto de que en 1775 determinó delegar la censura previa en censores fijos para cada periódico que, en ocasiones, eran personas individuales y, en otras, determinadas corporaciones, academias, etc. Diez años después, la madurez del fenómeno periodístico se reflejaba en la Real Orden de 19 de mayo de 1785 , primera medida legislativa específica para la prensa; entonces

10 Uno de los afortunados fue el Diario de los literatos, al que ayudaba el bibliotecario mayor del Rey, Blas Antonio Nasarre, y algunos académicos.

11 Cfr. Marcelin DefourneauX, Inquisición y censura de libros en la España del siglo XVIII, Madrid, Taurus, 1973. 
se independiza totalmente la censura de los periodicos con respecto a la de los libros, dependiendo la primera del Consejo de Castilla y la segunda del Juez de Imprentas, que es quien nombrará a los censores. La Real Resolución de 2 de octubre de 1788 es un documento decisivo en relación con la prensa del XVIII, ya que reúne en sí todas las disposiciones dadas hasta entonces sobre todos los aspectos.

Si a alguien le ha sorprendido que no hayamos hablado de la Inquisición, es porque ésta solo actuaba «a posteriori», ordinariamente como consecuencia de una denuncia, retirando lo que consideraba improcedente, pero no vetando de antemano una publicación. En cualquier caso, su efectividad fue muy limitada bajo Carlos III, que no estaba dispuesto a consentir el poder que ésta se arrogaba, sin que estuviese bajo el control de la corona.

Quizá merezca también una explicación el hecho de que el punto de referencia constante en esta exposición sea Madrid. No es que no hubiera prensa en provincias, pero el centralismo borbónico es visible también en la preponderancia de la prensa de la capital frente a la de provincias. No hay más que buscar en el Ensayo de una biblioteca de los mejores escritores del reinado de Carlos III (Madrid, Imprenta Real, 1789), de Sempere y Guarinos, la voz «Papeles periódicos», para comprobar que solo menciona dos de provincias: el Semanario literario y curioso de la ciudad de Cartagena y el Diario Pinciano, de Valladolid. ¿Se leía menos en provincias que en la capital? Es difícil saberlo. Ya hemos comentado el alto índice de analfabetismo que había, y además no se puede calcular cuántas personas leían un mismo periódico, porque las tiradas oscilan mucho, y ya en la época de las suscripciones, que ayudarían a hacer cálculos, resulta que los abonados no eran solo particulares, sino también entidades, como las Sociedades Económicas de Amigos del País, o las Academias, de modo que cada ejemplar podía pasar por muchas manos.

\section{PERIODISMO, LIBROS, LITERATURA}

Una vez trazado este rápido panorama, podemos decir que, desde la fundación del Diario de los literatos, la literatura encontró en la prensa un nuevo cauce de expresión. La propia evolución semántica de la palabra «prensa» -hacía notar François López- pone de manifiesto que si antes servía para denominar la industria que posibilitaba la existencia de los libros, ahora pasa a significar la principal producción de esa industria, que son los periódicos, pero es un hecho que, en el siglo XVII en algunos países, y en España en el XVIII, 
«gran parte de la prensa se pone al servicio del libro, dándolo a conocer, favoreciendo su difusión con muchísima más eficacia de la que se puede esperar de los catálogos publicados por las casas editoriales para los libreros y los particulares» ${ }^{12}$.

Lo literario en el XVIII, como es sabido, abarcaba muy amplio contenido. El Diccionario de Autoridades, en 1734, definía la literatura como «El conocimiento y ciencia de las letras» y las «Letras» eran entonces «las ciencias, artes y erudición». Faltaba resaltar el valor estético que después se ha considerado característica esencial de lo literario como algo artístico, como «arte bello que emplea como instrumento la palabra», dijo después el Diccionario de la Academia. Por eso, el leer en la cabecera de un periódico del XVIII el término «literario» (Mercurio literario, Gaceta literaria...) puede llamar a engaño. Afortunadamente, los títulos -en ocasiones muy prolijos y detallados, de un barroquismo decadente-, suelen explicitar el contenido. Si alguien oye hablar del Espíritu de los mejores diarios literarios que se publican en Europa -título ya bastante largo-, puede pensar que va a encontrar material específico para la investigación literaria. Y si se entera de que continúa: dedicado a los literatos y curiosos de España, es posible que se ratifique en su suposición. Pero el título sigue: que contiene las principales noticias que ocurren en las Ciencias, Artes, Literatura y Comercio; varias anécdotas curiosas; el anuncio de las obras que se publican, las invenciones que se hacen y los adelantamientos de las Ciencias. Volviendo a la biblioteca de Jovellanos, encontramos que el inventario se divide en dos grandes secciones: «Jurisprudencia», que abarca la eclesiástica y la civil, y «Literatura», bajo la que se encuentran los apartados de Humanidad, Bellas Letras, Filosofía, Historia y Varia erudición. Así de amplia era en el XVIII la idea de lo «literario» y de los intereses de un hombre «literato».

Sin embargo, también la literatura, tal como la entendemos hoy, encontró en los periódicos un nuevo medio de darse a conocer.

\section{PERIÓDICOS DIECIOCHESCOS DE CONTENIDO LITERARIO}

Los periódicos de contenido literario se fueron perfilando como respuesta a una necesidad. En España no existra ninguna publicación semejante a las $M e ́$ moires de Trévoux francesas, que informaban de las novedades bibliográficas 
del país y de fuera de él, y que fundadas en 1701, todavía a la altura de 1720 no incluían publicaciones españolas, al parecer por falta de noticias.

Surgieron así algunos periódicos -de largos y barrocos títulos-cuya única importancia reside en ser antecedentes del Diario de los literatos, primer periodico con verdadero interés literario, que sienta precedente, que crea escuela. El Diario se inspiraba en dos publicaciones francesas: el Journal des Savants y las Mémoires de Trévoux. Nació por iniciativa de un grupo de intelectuales en la tertulia del académico de la Historia Julián de Hermosilla. El título completo era Diario de los literatos de España: en que se reducen a compendio los escritos de los autores españoles, y se hace juicio de sus obras, desde el año MDCCXXXVII. Algunos párrafos del proyecto de los autores, tal como se exponía en el primer número del Diario nos ayudarán a captar el interés que tenía:

Contendrá este Diario los extractos de los libros de España (de todas las materias, se entiende] que van saliendo al público de tres en tres meses: y por cuanto no todos los trimestres habrá libros suficientes para llenar un volumen como éste, se irán entremetiendo extractos por su orden de los que salieron desde el principio del reinado de nuestro monarca Filipo V (que Dios guarde) y concluidos éstos, se pondrán en su lugar extractos de los mejores libros extranjeros; pero en todo tiempo se pondrán las noticias literarias de todos los reinos literarios: para cuyo efecto hay correspondencia establecida con personas sabias y poderosas, que facilitará la comunicación y puntualidad.

Se incluirán también en este Diario cualesquiera tratados, proyectos, memorias o disertaciones manuscritas que sus autores quisieren comunicar al público, para asegurarse de la aceptación que les merecen a los doctos, o para beneficio común, y pedir noticias a los que pudieren coadyuvar en sus trabajos literarios.

Y en cuanto a la concepción de la literatura y de su influjo es muy enjundioso otro párrafo de la Introducción:

$Y$ en atención a que el mayor beneficio que puede recibir el público es el de conocer el carácter de los libros que se le proponen para su ensefranza o diversión, en lo que muchas veces recibe tanto daño como en el uso de las cosas más perjudiciales de la vida humana, y se puede colegir, entre otras, del espiritu caballeresco, puntualidades ridículas en el trato civil, y de las costumbres cómicas amatorias, que aún se conservan en nuestra España, dimanadas de la frecuente lección de los libros de Caballerías, de Novelas y de Comedias de amores, que por lo arduo y maravilloso fueron las delicias de los siglos pasados: creemos estar obligados a advertir con la equidad más urbana de los 
errores cometidos en materias de literatura, y dar a conocer sin lisonja las delicadezas de cada arte en particular.

A pesar de las esperanzas que hace concebir, hay que reconocer que no son muchas las páginas del Diario dedicadas a la crítica de obras literarias.

Un fiel seguidor del Diario de los literatos fue el Mercurio literario (173940), que tenía periodicidad mensual. En el reinado de Felipe $V$ no hubo más periódicos literarios, sin embargo tanto la Gaceta de Madrid (que había nacido en 1661), como el Mercurio histórico y político (fundado al año siguiente del Diario de los literatos, 1738), ambos periódicos oficiales, que sobrevivirán a todos los altibajos del periodismo del XVIII, son una buena fuente de datos para el estudio de la literatura de ese siglo. Si mencionamos el único periódico literario en la España de Fernando VI, que fue el titulado Resurrección del Diario de Madrid o nuevo cordón crítico general de España, creado en 1748 por un tal fray Juan de la Concepción, llegamos al reinado de Carlos III.

Mariano Nifo (personaje pintoresco, considerado el primer periodista «profesional» de España, que llegó a editar nueve periodicos en los doce primeros años de este reinado) crea entonces el Cajón de sastre literario, que como su nombre da a entender, es una publicación miscelánea. En los años 176061 salieron siete volúmenes, pero precisamente por el carácter intemporal de su contenido, y por el interés que en sí mismo tenía, se reimprimió en 1781 , en 6 volúmenes. En sus páginas aparecieron por primera vez en un periódico, textos de autores clásicos españoles, como Jorge Manrique, Juan del Encina, Torres Naharro, fray Luis de León, Quevedo, Góngora, Gracián..., seleccionados por su contenido moral y didáctico.

El Novelero de los estrados y tertulias y diario universal de las bagatelas (1764) también tenía carácter antológico, y aunque figuraba como autor Antonio Ruiz Minondo, se cree- ya lo creía Sempere y Guarinos- que se trata de un seudónimo del mismo Nifo, autor también del Diario extranjero -que en realidad era semanal- en la misma línea abierta por el Diario de los literatos. El Novelero estaba dirigido a las mujeres, consideradas principales lectoras de novelas, y por ello insertaba traducciones, sobre todo de las de Marmontel: La buena madre, La mala madre, La escrupulosa o el amor descontento de si mismo, $O$ todo o nada, Las dos desgraciadas felices; y también de Matías de los Reyes: La desobediencia de los hijos castigada y El heroísmo de la amistad ${ }^{13}$.

13 Cfr. Teresa Barjau Condomines, eIntroducción a un estudio de la novela en España (1750-1808)», BOCES XVIII, 10-11, págs. 115-116. 
La Aduana crítica (1763) no disimulaba su filiación con respecto al Diario de los literatos. El título muestra a las claras el propósito -tan acorde con las ideas ilustradas- de filtrar las lecturas con un criterio ético en el más amplio sentido. El fundador de la Aduana, Flores de la Barrera, hacía una declaración de intenciones en el primer número: «precaver los estragos a que se expone la Literatura si no se contienen los delitos y fraudes que con dolor vemos ejecutarse cada día. Se admiran los plagios que impunemente cometen algunos que aspiran al carácter de autores; se tocan falsedades, se notan imposturas...; se adulteran los textos...; se ven autoridades truncadas...; las que son traducciones quieren que se reputen obras originales"...

El Correo literario de la Europa $(1781-82 ; 1786-87)$ muestra que las opiniones sobre la novela, tan negativas en 1737 tanto por parte de Luzán como del Diario de los literatos, han evolucionado y ya merecen en la década de los ochenta otra consideración, por lo menos en cuanto a la atención y espacio que se le dedica, semejante al que ocupa el teatro, un género siempre tan bien considerado. Esto no significa que las críticas a las novelas concretas sean elogiosas en general, pero en cualquier caso el Correo -en palabras de $\mathbf{M}^{\mathbf{N}}$ José Alonso Seoane- «viene a representar, al comienzo de los años ochenta, el papel de un intermediario más con respecto a la novela europea, y particularmente a la francesa, en España» 14 .

El Belianís literario (1765) es otro periódico en el que la literatura está presente hasta en el título, que no esconde su propósito de proteger a «los escritores desamparados y doncellas menesterosas». La cabecera completa dice: Belianis literario. Discurso andante, dividido en varios papeles periódicos y en defensa de algunos puntos de nuestra bella literatura (...) Su autor, Patricio Bueno de Castilla, que era seudónimo de Juan José López de Sedano.

También dirigía Nifo la Tertulia de la aldea, que aunque apareció por entregas en 1768 , llegó a reimprimirse en $1775-76$ por esa cierta intemporalidad que le otorga su carácter misceláneo. Quizá sea suficiente leer el título completo para hacernos una idea de sus propósitos: Tertulia de la aldea y miscelánea curiosa de sucesos notables, aventuras divertidas y chistes graciosos, para entretenerse las noches del invierno y del verano.

Dejando aparte El Censor (indudablemente la publicación más importante de este período, pero que no se puede calificar de literaria), nos encontramos en este recorrido diacrónico con el periódico literario más interesante del XVIII, junto con el Diario de los literatos. Me refiero al Memorial literario, fundado por Pedro Trullench y Joaquín Ezquerra en 1784 y que al año de su

14 M" José Alonso SEOANE, «La novela en el Correo literario de la Europa*, PIE, pág. 25. 
nacimiento tenía la considerable cifra de 715 suscriptores. De su interés habla el hecho de que, habiendo sido suprimido en 1791, como toda la prensa no oficial, reapareció durante el ministerio del Conde de Aranda y existio hasta 1808.

Si mencionamos ahora el Gabinete de lectura española $(1787-88 ; 1793)$, de Isidoro Bosarte, del mismo tipo didáctico-antológico que el Cajón de sastre literario, de Nifo, ya solo nos quedan tres publicaciones importantes por su contenido literario, especialmente en lo que al teatro se refiere. Dos de ellas fueron fundadas y dirigidas por dramaturgos: el Semanario erudito (1787-1791), de Antonio Valladares de Sotomayor, y el Diario de las musas (1790-91), de Luciano Comella. El tercer periódico, La espigadera (1790-91), de un tal Bravo, catedrático de Valladolid, contiene interesantes críticas y reseñas teatrales. El Semanario erudito interesa además para la historia de la literatura española no dramática, por algunas colaboraciones, como las notas que Macanaz publicó sobre el Teatro crítico universal de Feijoo (VII, 205-280 y VIII, 1-24), y sobre los dos primeros tomos de las Cartas eruditas y curiosas (VIII, 125-135 bis): incluye en estas notas los fragmentos que más le interesan y extracta las obras. Fray Martín Sarmiento explica en las páginas del Semanario la razón por la que no publica El porque sí y el porque no (VI, 111-188), e inserta además un interesante «Catálogo de algunos libros curiosos y selectos, para la librería de algún particular que desee comprar de tres a cuatro mil tomos» (1748-1754) (V, 97174). También contiene el Semanario una carta del padre Isla ${ }^{15}$.

Estos tres periódicos, el Semanario erudito, el Diario de las musas y La espigadera cesaron en 1791, reinando ya Carlos IV. La Real Resolución del 24 de febrero de ese año, por la que se suspendió toda publicación periódica no oficial (de modo que solo pervivieron la Gaceta y el Mercurio, y el Diario de Madrid) dio al traste de momento con un periodismo que iba superándose a sí mismo. El temor a lo que estaba sucediendo en Francia desde 1789 fue la causa de esta y otras muchas medidas que se tomaron, para impedir que penetraran en España los vientos revolucionarios.

\section{MODOS DE PRESENCIA DE LO LITERARIO EN LOS PERIÓDICOS}

Una vez trazada esa panorámica cronológica de la prensa más o menos literaria del XVII, ya solo nos queda señalar de qué manera estaba presente la

15 Cfr. Rosalia Fernández CABezón, «La literatura del siglo XVIII en el Semanario Erudito», PIE, págs. 171-180. 
literatura en las páginas de esas publicaciones, qué interés puede tener para el investigador actual de la literatura el conocimiento de la prensa en el siglo ilustrado.

1. Existía por una parte la información bibliográfica. No siempre, es verdad, relativa a las «bellas letras», pero sí en creciente medida. La Gaceta de Madrid, que no es una publicación literaria, ofrecía noticias de libros, hasta el punto de ser la mejor fuente de información -también por tratarse de un periodico muy longevo gracias a su carácter oficial- para estudiar la historia del libro en España en el siglo XVIII, desde los diversos puntos de vista: económico, industrial, temático, etc.

Pasando por alto el Diario de los literatos, que también ofrecía información bibliográfica y al que nos referiremos después, encontramos que el $\mathrm{Mer}$ curio literario (1739-40), el Diario extranjero (1763), el Mercurio histórico y político, el Correo literario de la Europa (1781-82 y 1786-87), el Memorial literario (1784-1808), la Biblioteca periódica anual (?-1791) y el Espíritu de los mejores diarios literarios que se publican en Europa (1787-1791), son espléndidas fuentes para el estudio de la recepción literaria en el siglo XVIII. Cada uno de estos papeles canalizaba las noticias de las publicaciones extranjeras y daba noticia de lo que se editaba en España.

2. Otros periódicos añadían a la mera información, la crítica de libros. La crítica literaria periodística (cuando hablo de crítica literaria me refiero a la crítica en sí, no a que sean literarias las obras criticadas ${ }^{16}$ ) nace en España con el Diario de los literatos, que incluía recensiones -más de 80 libros fueron comentados, según Guinard- hechas por los editores o por colaboradores eventuales como Juan de Iriarte, a quien se debe en parte la recensión de la Poética de Luzán (tomo IV, art. 1). También insertaban reseñas El Observador, de José Marchena, la Miscelánea instructiva, e incluso un peribdico oficial como el Mercurio histórico y político.

3. Pero no solo era la prensa vehículo de noticias sobre libros. También está presente la literatura como creación. Muchos periódicos incluían en sus páginas poesías más o menos prosaicas pero, a fin de cuentas, composiciones en verso, lo que implica una voluntad artística por parte de sus autores. El material es tan considerable que ha dado lugar a volúmenes como el findice de las poesías publicadas en los periódicos españoles del siglo XVIII (Madrid, CSIC, 1981), de Aguilar Piñal, catálogo de 5.422 entradas; o el trabajo de M.' Teresa Bautista Malillos, Poesías de los siglos XVI y XVII impresas en el siglo XVIII

16 En esto sigo el mismo criterio de Jesús Castañón en su libro La critica liseraria en la prensa espafiola del siglo XVIII (1700-1750), Madrid, Taurus, 1973. 
(Madrid, CSIC, 1988), aunque este último no trate exclusivamente de las publicadas en la prensa. En el Correo de Madrid, o de los ciegos aparecieron poesías inéditas de Tomás de Iriarte, de Meléndez, de Cadalso. El poeta, de Nicolás Fernández de Moratín, estaba totalmente redactado en verso, hasta el punto de que se duda en considerarlo publicación periódica, aunque materialmente lo fuera ${ }^{17}$. En El bufón de la Corte (1767) las composiciones en verso suelen tener carácter satírico: la sátira fue un género de amplio desarrollo en el XVIII por lo que tenía de «pedagógico»: se pretendía corregir las costumbres a base de zaherirlas con las armas de la sátira. El Mercurio literario (1739-40), la Miscelánea instructiva o el Diario de las Musas (1790-91) también incluían poesías: Irene Vallejo ha estudiado las de este último periódico, en el que vieron la luz composiciones de Cadalso e Iglesias de la Casa, entre otros ${ }^{18}$. Incluso el famoso Censor (1781-1788), en donde lo propiamente literario es lo más flojo del periódico, dio cabida en sus páginas a composiciones poéticas. En El Censor se publicó por primera vez La despedida del anciano, de Meléndez Valdés y las dos Sátiras a Arnesto de Jovellanos. En realidad casi todos los poetas del XVIII publicaron algún poema en la prensa, y en muchos casos se trata de la primicia. Esto sin contar las muchas poesías de autores clásicos grecolatinos o españoles.

4. El despertar de un nacionalismo que se fue acentuando a medida que avanzaba el siglo fue el motivo por el que una serie de periodicos rescataron del olvido, insertándolos en sus páginas, textos antiguos u olvidados de autores españoles. Antes he hablado, como de pasada, de algunos autores presentes en el Cajón de sastre literario, de Nifo. En La tertulia de la aldea (1775), además de fragmentos de Boccaccio, se insertaron episodios del Quijote, de las Novelas ejemplares, y algunas obras de María de Zayas. Guinard identificó -porque no se dice quiénes son los autores de las obras, que con frecuencia se ofrecen resumidas- textos de La española inglesa, La fuerza de la sangre y La señora Cornelia, de Cervantes, y El juez de su causa, de María de Zayas. Además, Fernández Insuela ha identificado más recientemente resúmenes de La gitanilla (II, 1, 3-20) y La ilustre fregona (II, VII, 3-19); de Tarde llega el desengaño (I, IX, 4-17), La inocencia castigada (1, XI, 5-18), Estragos que causa el vicio (II, III, 3-19), La perseguida triunfante (II, V, 3-25)

17 De acuerdo con Guinard, cuando hablo de «periódicow, me refiero a una publicación destinada a un colectivo de lectores, no a un único destinatario, con un contenido de actualidad, que se publica con determinada periodicidad, y cuyos números guardan cierta relación entre sf, ya por el contenido, ya por la regularidad de sus secciones, relación que en ocasiones es visible en la paginación correlativa de los números.

18 Cfr. Irene Vallejo Gonzalez, *La poesía en el Diario de las Musas», PIE, págs. 517-522. 
y La burlada Aminta (II, IX, 3-14), de María de Zayas; y de varios textos procedentes del David perseguido, de Cristóbal Lozano ${ }^{19}$. También hay muchos cuentos tradicionales.

El Gabinete de lectura española $(1787-88,1793)$ (significativamente lleva el adjetivo «española» en el título), de Isidoro Bosarte, también rescató textos olvidados e incluso inéditos de nuestro siglo de oro. Publicó una versión inédita de la República literaria de Saavedra Fajardo, y dio a conocer -en los números 4 y 5 - las versiones de Rinconete y Cortadillo y de El celoso extremeño según el manuscrito Porras. (Hago un inciso para señalar que la República literaria tuvo una notable influencia sobre la crítica literaria en el XVIII. De hecho a lo largo del siglo tuvo diez reediciones, y es muy frecuente en estos periódicos referirse a la «república de las letras», con clara evocación de la obra de Saavedra Fajardo).

5. Por otra parte, lo que se ha llamado la batalla del teatro en el siglo XVIII se libró primordialmente en las páginas de los periódicos. A través de las del Memorial literario (1784), del Diario de Madrid (1785), del Correo de los ciegos (1786), de La espigadera (1790), logró difundirse una nueva mentalidad acerca del hecho teatral, muy en la línea de los principios que exponía Luzán en su Poética. En 1790-91, el Diario de las musas, de Luciano Comella es, según Emilio Palacios, «la voz habitualmente silenciada, porque no representa ni a las instancias gubernamentales ni a los reformistas neoclásicos» 20 . La crítica teatral que alli se hacía evitaba entrar en cuestiones teóricas, porque tropezaba con los partidarios de las reformas, así que se limitaba al comentario de obras concretas, con talante más positivista (el Diario extranjero, de Nifo, había sido el primero en incluir una crónica teatral).

Pero antes de estos años, la prensa fue una palestra decisiva de la batalla que condujo a la prohibición de los autos sacramentales en 1765 . No se puede hablar de la polémica en torno a los autos sin mencionar El Pensador (1762-63, 1767), de Clavijo y Fajardo, que junto con Nicolás Fernández de Moratín en su opúsculo Desengaños al teatro español, protagonizó una verdadera campaña en los años 60. De sus primeros 52 números -de 1761-62, porque luego resurgió y volvió a desaparecer en 1767- están dedicados al tema del teatro los números III, IX, XXII, XXVI, XXVII, XL y XLII. Los dos últimos son los capitales en el ataque a los autos. El profesor Caso llega

19 ANTONIO FERNÁNDEZ INSUELA, «Notas sobre la narrativa breve en las publicaciones periodicas del siglo XVIII: Estudio de La Tertulia de la Aldea», PIE, págs. 181-194.

20 EMILIO PALACIOS, «Diario de las Musas: Una propuesta de reforma del teatro español a fines del siglo XVIII», $P I E$, pág. 351. 
a aventurar que alguno de los «pensamientos» de El Pensador pueda deberse a la pluma de Moratín, dada la llamativa coincidencia de ideas, pero la verdad es que para defender una misma postura, Clavijo suele apelar preferentemente a argumentos de índole religiosa y Moratín sin embargo a razones de tipo artístico. El caso fue que Clavijo y Moratín vencieron, al ser prohibidas en 1765 la representaciones de los autos, lo que significó un triunfo para los ilustrados.

El más destacado enemigo de las ideas de Clavijo en esta contienda fue el periódico titulado El escritor sin título (1763-64), defensor de Calderón y de las representaciones de autos sacramentales, pero de la desigualdad de la lucha habla el hecho de que El Pensador fue un periódico importante, que llegó a tener 86 números, mientras que El escritor sin título no pasó de 11.

6. Una última vinculación entre el fenómeno periodístico y lo literario en el siglo XVIII la encontramos en la influencia del medio sobre la propia escritura: la ficción epistolar, tan adecuada a los condicionamientos de la prensa periódica, adquiere un desarrollo importante en el XVIII. Es bien sabido que las Cartas marruecas, de Cadalso, se publicaron por vez primera en el Correo de los ciegos en $1788^{21}$, y posteriormente en El Censor. Pero es que hubo otras muchas «cartas» en la prensa, que no se recopilaron luego en tomo, y que no tienen la relevancia de las de Cadalso, y sin embargo son prueba de la pujanza de la ficción epistolar como modalidad literaria.

El ensayo también se vio potenciado por la prensa periódica. En realidad los números de El Pensador y de El Censor no son otra cosa que ensayos, llámense «pensamientos» o «discursos». Precisamente «discursos» se denominan los de El Censor y se titulaban los de Feijoo en el primer tercio del siglo.

El reverso de la medalla en las relaciones prensa-literatura se da cuando la creación literaria es fuente para el estudio de la prensa del XVII ${ }^{22}$. Pero hemos de terminar, y basta con dejarlo apuntado.

- Este articulo resume el texto de la conferencia pronunciada en la Universidad de CastillaLa Mancha el 25 de enero de 1994, dentro del ciclo Mundo literario y mundo editorial.

212 de febrero de 1788, un fragmento de la Carta VII; 30 de junio de 1788, Carta XLV.

22 Alberto González Troyano, en su artículo «Aproximación a La pensadora gaditana» (PIE, 261-264), aporta una serie de títulos de períbdicos extranjeros del XVIII, que se recibían en Cádiz, extrayéndolos de los sainetes de Juan Ignacio González del Castillo. 